\title{
A new patch antenna for ultra wide band communication applications
}

\author{
Anwar Sabah, Malik Jasim Farhan
}

Electrical engineering Department, College of Engineering, Mustansiriyah University, Iraq

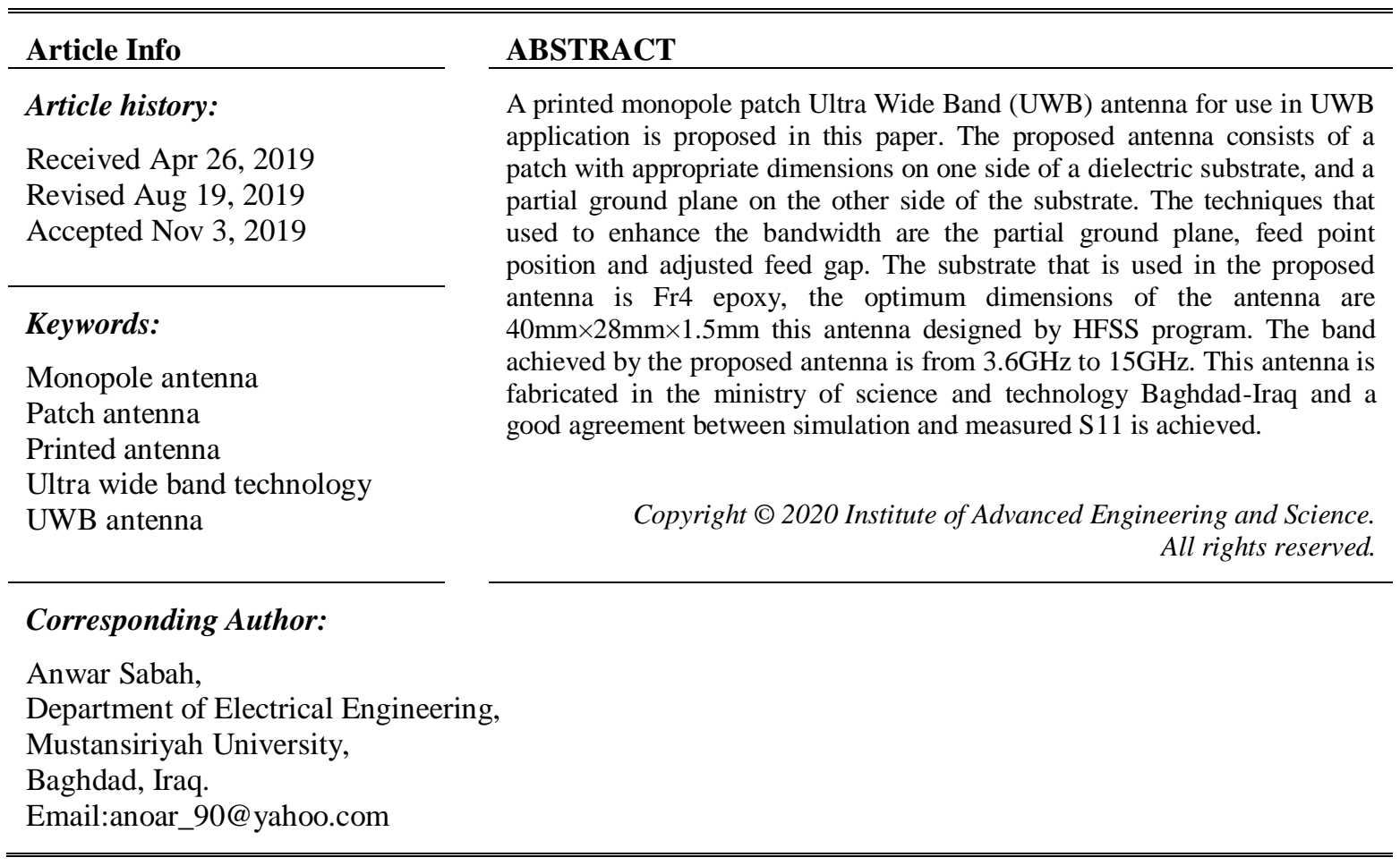

\section{INTRODUCTION}

In communication systems, there are constantly demand to increase the rate of data transfer $[1,2]$. The increase the rate of transfer information can be achieved by either increase SNR or bandwidth according to Shanon-Nyquist (1) [3].

$$
\mathrm{C}=\mathrm{B} \log _{2}(1+S N R)
$$

Ultra-wideband is a technology used to increase the bandwidth, this technology is recognized by the Federal Communication Committee (FCC), it has a bandwidth of up to $7.5 \mathrm{GHz}$, from $3.1 \mathrm{GHz}$ to $10.6 \mathrm{GHz}$ [4-9]. This technology sends the data in form of a train of pulses instead of using carrier signal to transmit the data, the width of these pulses is very narrow estimated few nanoseconds, so it has a wide band spectrum $[10,11]$. The UWB system has advantages such as the power consumption is low because it does not use carrier signal, high data rate due to large bandwidth and low interference $[12,13]$. UWB antenna is an important element and plays an important role in the ultra-wideband system, it has features such as the size of it is small, its weight is light and low profile. These properties make it suitable to use in a portable device and it can be integrated with a circuit of radio frequency and it has simple structure so it is easy to fabrication, and its cost is low as well as it has high precision ranging [1, 14-16]. Due to physical features of monopole antenna such as small size, the cost of it is cheap, and simple combination making it good choice use as a UWB antenna [2, 11, 15, 17-23]. A patch antenna is the type of UWB antenna and it is a planar antenna consist of three layers the medium layer is a substrate it is a dielectric material the lower layer is printed on the lower side of the substrate is a conductive sheet called ground plane and an upper layer called patch. 
The patch can be in different shapes such as rectangular, circular and any other shape printed on the upper side of the substrate is a conductive material in different shapes called patch with the feed line [24].

In this paper, the design and optimization of the printed patch ultra-wideband antenna is presented. A strip feed line technique used to feed the radiator element, the proposed antenna designed by using High Frequency Structure Simulator (HFSS) software program and fabricated in the ministry of science and technology by using Fr4 epoxy substrate. This paper show simulation and the measured result of return loss and compare between them and show a simulation result of the radiation pattern, gain, and current distribution.

\section{ANTENNA GEOMETRY}

This patch antenna consists of the dielectric substrate and finite ground plane printed on the lower surface of the substrate and patch with feeder printed on the upper surface of the substrate. The form of the patch is a merge of a square with three triangles shown in Figure 1. The dielectric used is Fr4 epoxy has a dielectric constant 4.4, loss tangent 0.02 and thickness $1.5 \mathrm{~mm}$. The feed technique used is microstrip feed line of $50 \Omega$ has a width $2.89 \mathrm{~mm}$ connected between the port and patch for exciting the radiator. There is a relation between the lower edge frequency of bandwidth of ultra-wideband and dimension of the patch so the dimension of patch calculated according to this (2) [25]:

$$
\mathrm{fl}(\mathrm{GHz})=\frac{7.2}{(\mathrm{D}+0.2785 \mathrm{D}) \sqrt{\mathrm{\varepsilon reff}}}
$$

Where:

$\varepsilon_{\text {reff }}$ is effective permittivity.

$\mathrm{D}$ is dimension of patch.

$\mathrm{f}_{1}$ is lower edge frequency.

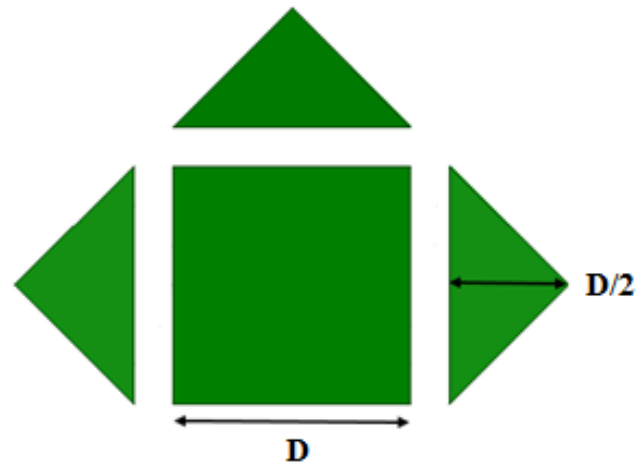

Figure 1. Patch shape

\section{PARAMETRIC STUDY}

Optimization is done to find the optimum dimensions of the proposed antenna by using the sweep parameters method.

\subsection{Effect of Ground Plane Width}

The first technique which is used to get wideband to achieve UWB requirement is a partial ground plane that means cut the ground plane. All parameters of design are fixed and chosen arbitrarily. To choose the optimum width of the ground plane different values are tested. Figure 2 shows the simulation of the effect of the ground width on the bandwidth.

It is clear that the bandwidth increase when the width of ground plane decrease until the width reach to $10 \mathrm{~mm}$ when the best matching impedance occurred so the best bandwidth achieved but when width ground plane decreases more than this value the bandwidth is decreasing so the best width of the ground plane is $10 \mathrm{~mm}$. 


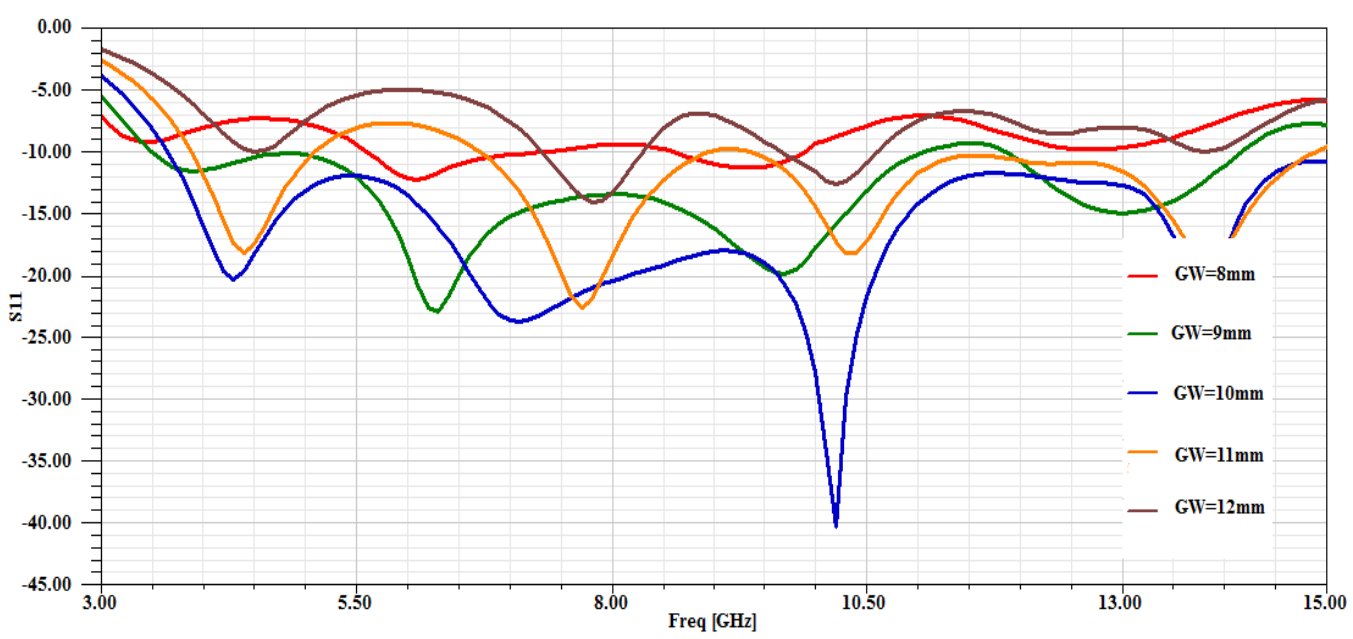

Figure 2. The effect of ground width on the bandwidth

\subsection{The Effect of Ground Plane Length}

The second parameter tested is the length of the ground plane when other parameters are fixed. Figure 3 shows different values of ground length, it is noticed that the change of ground length effect on the upper edge of bandwidth, the best value that achieved best matching impedance is $40 \mathrm{~mm}$, if the length of the ground plane is less or greater then this length the bandwidth is smaller and that means the matching impedance is worse.

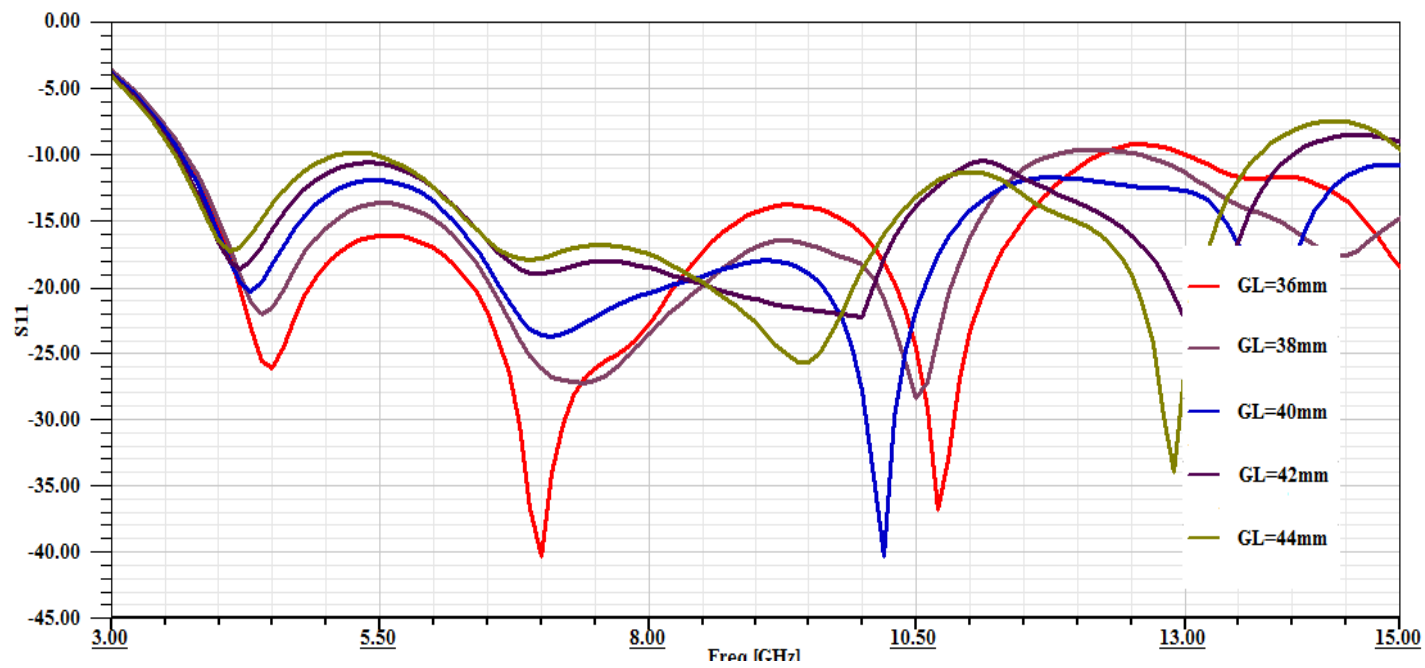

Figure 3. The effect of ground length and substrate length on bandwidth

\subsection{The Effect of Substrate Width}

The third parameter tested is the width of the substrate, this parameter has no large effect on the bandwidth so the less width that achieved a bandwidth of ultra-wideband is $28 \mathrm{~mm}$. Figure 4 shows the parameter test to find the best value of this parameter.

\subsection{The Effect of Feed Point Postion}

The fourth parameter tested is the feed point position at this test the required is to find the best connection point between the patch and the feed line to find the best matching impedance position. All points from the begging edge of the patch to the other edge of the patch are tested and the best feed point is that achieved to determine the best matching impedance, the best value is -3.163 , the Figure 5 showing the effect of feed point position on bandwidth. 


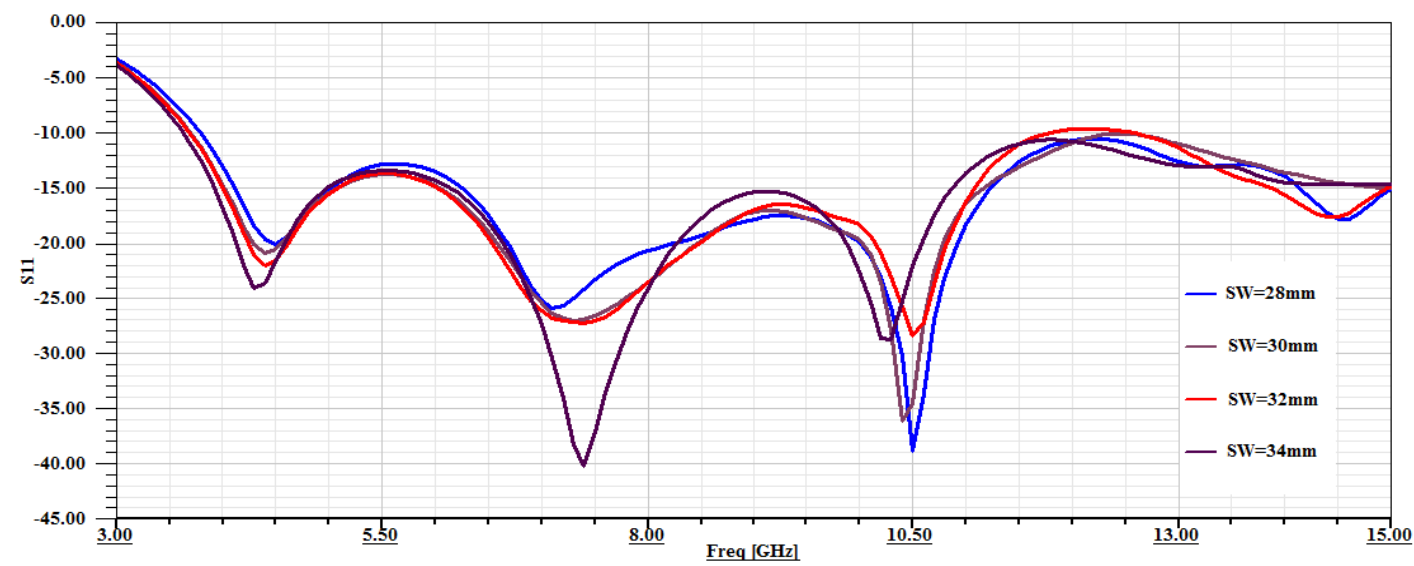

Figure 4. The effect of substrate width on bandwidth

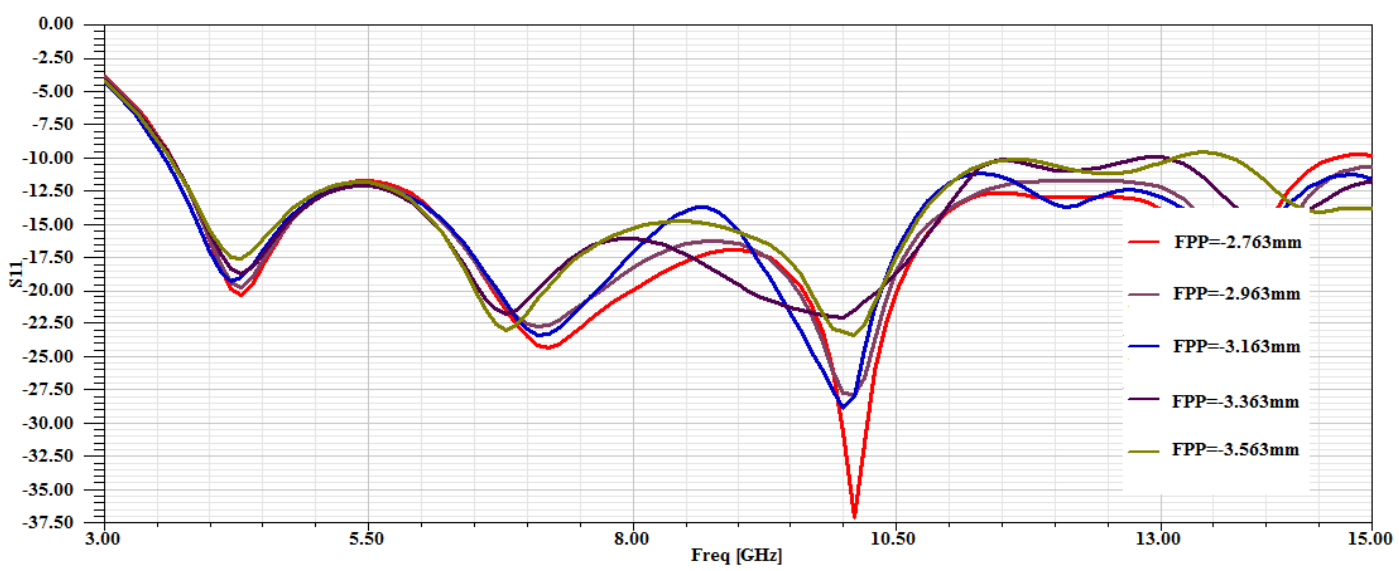

Figure 5. The effect of feed point position on band width

\subsection{The Effect of Feed Gap Dsitance}

The last parameter tested is feed gap distance, the feed gap is the distance between the top edge of the ground and the bottom edge of the patch this parameter has an important effect on the bandwidth. Figure 6 shows the different values of the feed gap tested to choose the best value of the feed gap that achieved maximum bandwidth. From this figure it is noticed that when the feed gap distance is equal to zero the bandwidth is small when this gap increases the bandwidth increase too until this distance equal to $0.4 \mathrm{~mm}$ the bandwidth reaches to its max value therefor; this value can be taken as the best value of this distance.

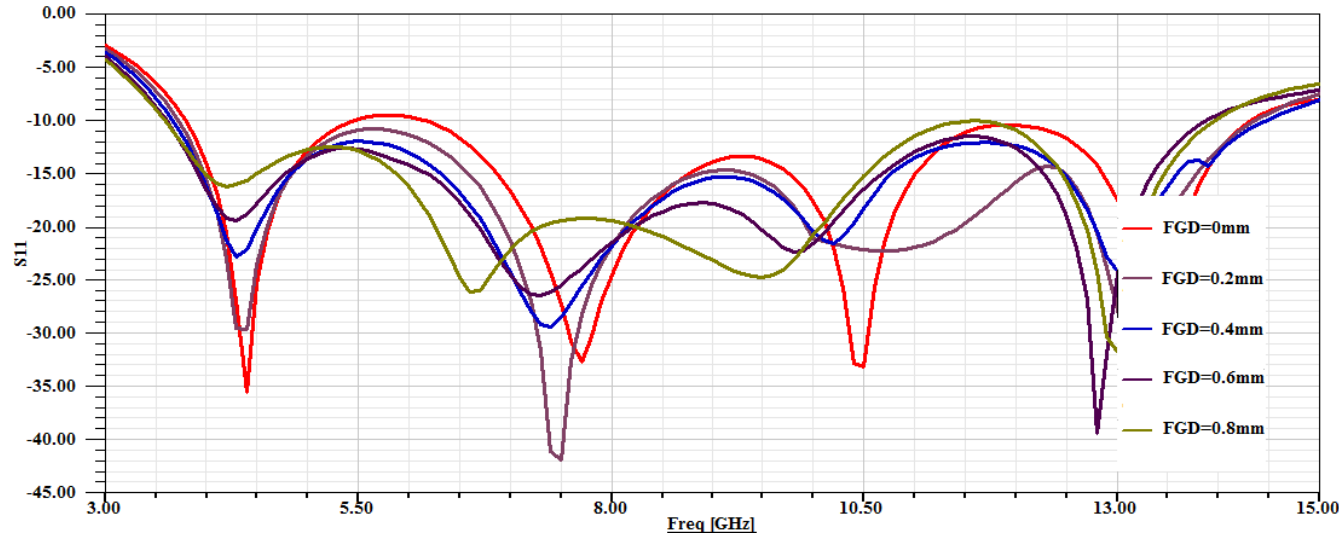

Figure 6. The effect of feed gap on band width 
The proposed patch antenna is shown in Figure 7. The optimum values of all parameters that affect the performance of the proposed antenna are presented in Table 1 and the reflection coefficient of the proposed antenna shown in Figure 8. The proposed antenna with its optimum dimension is fabricated in the ministry of science and technology Baghdad-Iraq as shown in Figure 9.

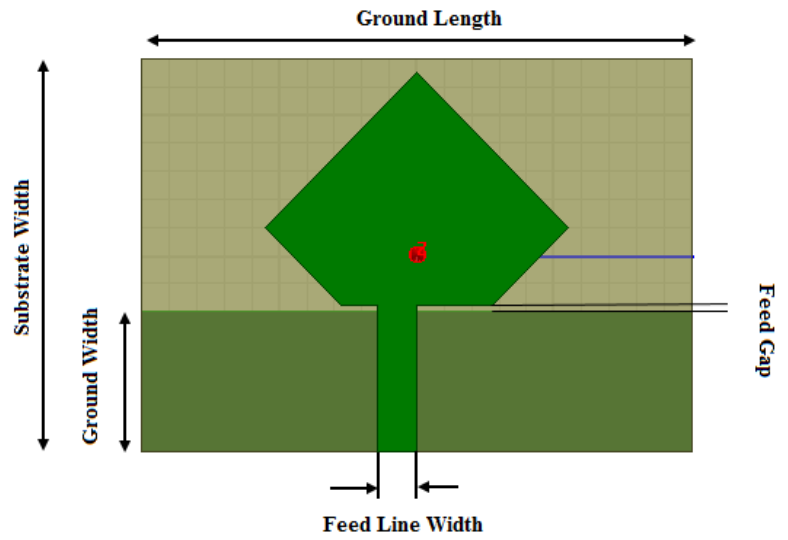

Table 1. Optimal Design Parameters of Proposed

\begin{tabular}{cc}
\multicolumn{2}{c}{ Patch Antenna } \\
\hline Parameter & Value (mm) \\
\hline Ground Width (GW) & 10 \\
Ground Length (GL) & 40 \\
Substrate Length (SL) & 40 \\
Substrate Width (SW) & 28 \\
Feed Point Position (FPP) & -3.163 \\
Feed Gap (FG) & 0.4 \\
Feed Line Width & 2.89 \\
\hline
\end{tabular}

Figure 7. Proposed patch antenna

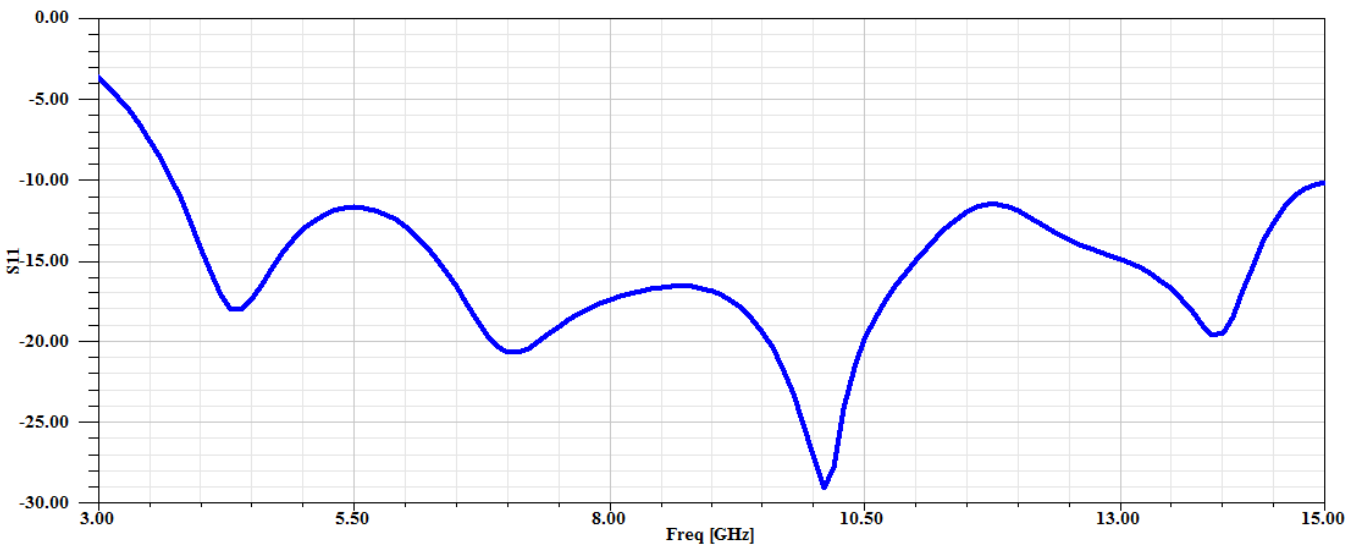

Figure 8. Simulated input reflection coefficient of proposed antenna
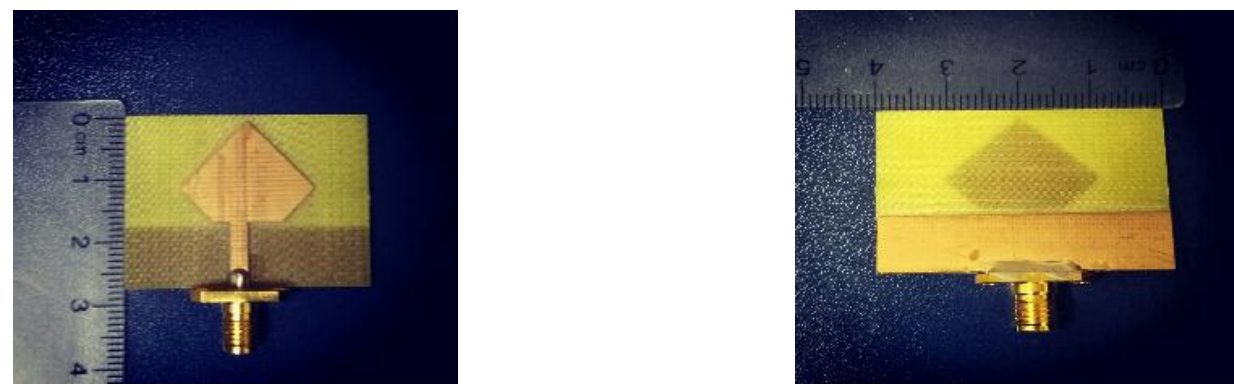

Top view Back view

Figure 9. Photo of the prototype patch antenna with optimum dimensions

\section{RESULT AND DISCUSSION}

The simulated results of the printed monopole patch antenna are obtained using the Ansoft simulation software High Frequency Structure Simulator (HFSS). Figure 10 shows input reflection 
coefficient S11in both cases simulated and measured for the designed antenna is lower than-10 dB from 3.6 $\mathrm{GHz}$ to $15 \mathrm{GHz}$ this band covered the required bandwidth for ultra-wideband technology. A good agreement between the simulated and measured result of S11with a simple shift to the right due to the effect of SMA connector, the tolerance of manufacture and impurities of the constructed materials.

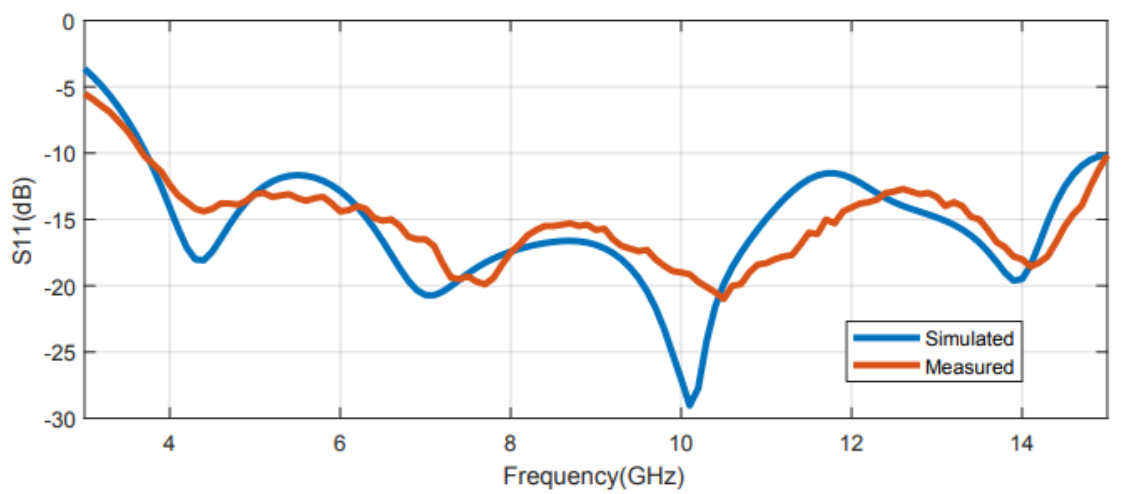

Figure 10. S11 comparison between simulation and measurement results

\section{CURRENT DISTRIBUTION}

The proposed antenna with optimum dimensions is simulated at different frequencies $4 \mathrm{GHz}, 8 \mathrm{GHz}$, and $12 \mathrm{GHz}$, and Figure 11 below show the simulation of current distribution at these frequencies. For the three different frequencies, the current distribution is mainly concentrated along the lower edge of the patch and along the transmission line at selected frequency but the distribution of current on the ground plane increase with frequency increased.

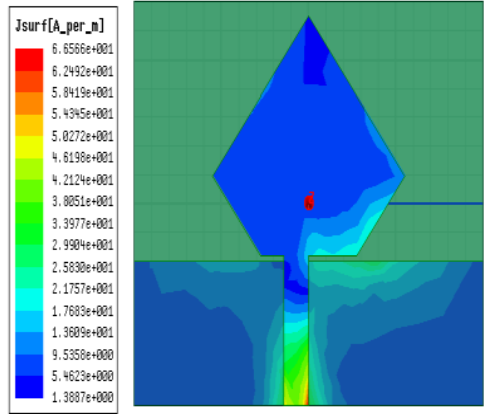

(a) $4 \mathrm{GHz}$

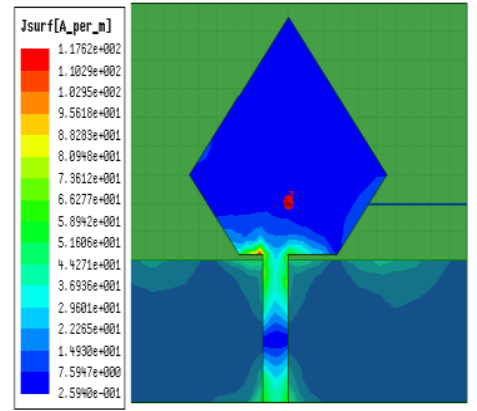

(b) $8 \mathrm{GHz}$

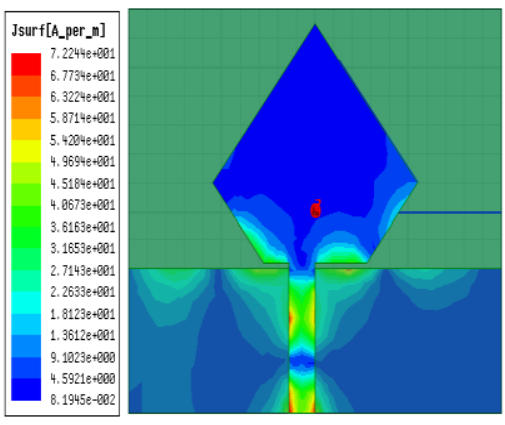

(c) $12 \mathrm{GHz}$

Figure 11. Current distribution of surface on the antenna structure: (a) at $4 \mathrm{GHz}$ (b) at $8 \mathrm{GHz}$ (c) at $12 \mathrm{GHz}$

\section{RADIATION PATTEN}

The simulated E-plane and H-plane radiation patterns of the optimal antenna structure are shown in Figure 12 below at frequencies $4 \mathrm{GHz}, 10 \mathrm{GHz}$, and $12 \mathrm{GHz}$ respectively. It is clear that these patterns have an omnidirectional pattern at a lower frequency and nearly omnidirectional at medium and high frequency, which are needed for UWB applications. Figure 12 shows the simulated radiation pattern at a different frequency over the range of UWB, both E-plane and H-plane are shown. 

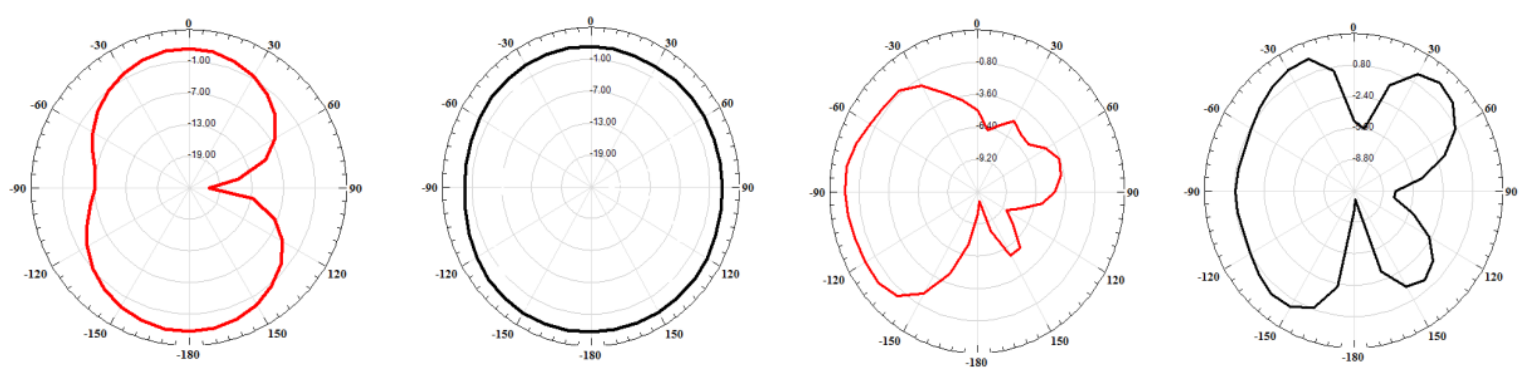

E-plane at $4 \mathrm{GHz} \mathrm{H}$-plane at $4 \mathrm{GHz}$ E-plane at $8 \mathrm{GHz} \mathrm{H}$-plane at $8 \mathrm{GHz}$

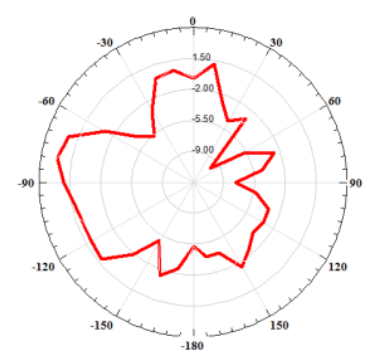

E-plane at $12 \mathrm{GHz} \mathrm{H}$-plane at $12 \mathrm{GHz}$

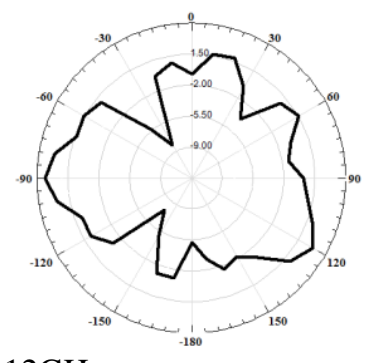

Figure 12. Radiation pattern: (a) $4 \mathrm{GHz}$ (b) $8 \mathrm{GHz}$ (c) $12 \mathrm{GHz}$

\section{GAIN}

Figure 13 shown the antenna gain versus frequency. The proposed antenna has relatively low gain at low frequencies and the gain gradually increasing, at medium frequencies little degradation occurred in gain the maximum gain is (6.1) dB.

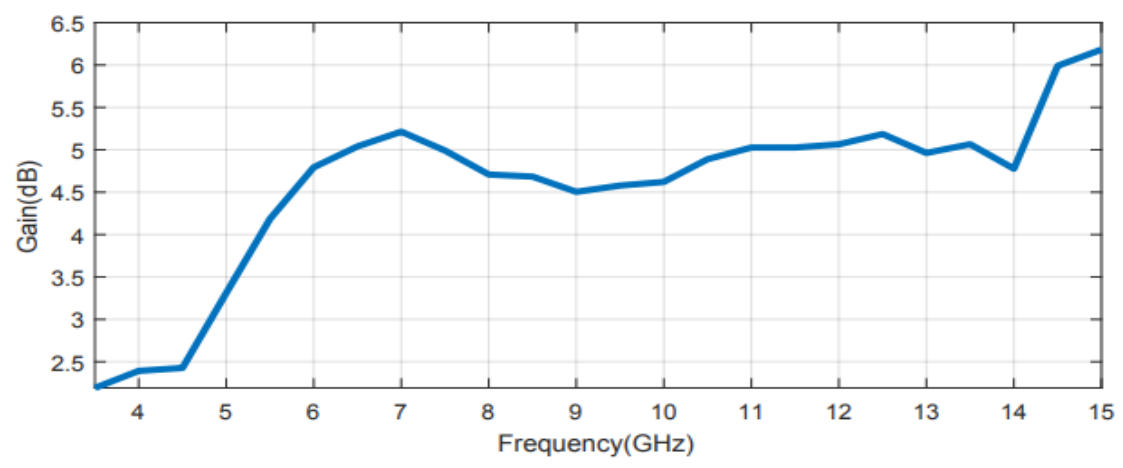

Figure 13. The gain versus frequency

\section{CONCLUSION}

A printed monopole patch UWB antenna is designed by HFSS program with optimum dimension $40 \mathrm{~mm} * 28 \mathrm{~mm} * 1.5 \mathrm{~mm}$ and it was fabricated. From the study of the parameters of the proposed antenna, we concluded that the change of feed gap effect on upper edge of bandwidth larger than the effect on the lower edge of bandwidth, when the feed gap equal to zero the bandwidth is small and the bandwidth increase when the feed gap increase until certain value and the change of ground length effect on upper edge of bandwidth, the results show the bandwidth of proposed antenna from $3.6 \mathrm{GHz}$ to $15 \mathrm{GHz}$ and maximum gain is $6.1 \mathrm{~dB}$, this antenna can be used in UWB applications.

\section{ACKNOWLEDGEMENTS}

The authors would like to thank Mustansiriyah University (www.uomustansiriyha.edu.iq) BaghdadIraq for its support in the present work 


\section{REFERENCES}

[1] Y. Rahayu, T. A. Rahman, R. Ngah, and P. S. Hall, "A small novel ultra wideband antenna with slotted ground plane A Small Novel Ultra Wideband Antenna with Slotted Ground Plane,", International Conference On Computer and Communication Engineering, no. June, 2008.

[2] Mohammed Al-Husseini, Ali Ramadan, Youssef Tawk, Ali El-Hajj, and Karim Y. Kabalan, "Design and Ground Plane Consideration of a CPW-Fed UWB Antenna", International Conference on Electrical and Electronics Engineering (ELECO), 2009.

[3] B. Gupta, S. Nakhate, and M. Shandilya, "A compact UWB microstrip antenna with modified ground plane for bandwidth enhancement," Int. J. Comput. Appl., vol. 49, no. 19, 2012.

[4] A. A. K. G. R. D. M. N. B. S. Virdee, "Ultra-wideband circular slot antenna with reconfigurable notch band function,", IET Microwaves, Antennas \& Propagation, vol. 6, no. June 2011, pp. 108-112, 2012.

[5] A.H. Majeed and K.H. Sayidmarie "UWB elliptical patch monopole antenna with dual-band notched characteristics", International Journal of Electrical and Computer Engineering (IJECE), vol.9, no.5, pp.3591-3598, 2019.

[6] Majed O. Al-Dwairi "A planar UWB semicircular-shaped monopole antenna with quadruple band notch for WiMAX, ARN, WLAN, and X-Band", International Journal of Electrical and Computer Engineering (IJECE), vol. 10, no. 1, pp.908-918.

[7] A. S. Abdullah and M. J. Farhan "A Novel Two Open Terminals Slot Antenna for Ultra Wideband Wireless Communication Applications" 1st International Scientific Conference of Engineering Sciences - 3 rd Scientific Conference of Engineering Science (ISCES), 2018.

[8] A. S. Abdullah and M. J. Farhan "A Novel Heptagonal Slot Antenna for Ultra Wideband Wireless Communication Applications" Journal of Engineering and Development, vol. 18, no.6, pp. 1813-7822, 2014.

[9] Giorgos TATSIS, Vasilis RAPTIS, and Panos KOSTARAKIS, "Design and Measurements of Ultra-Wideband Antenna ", Int. J. Communications, Network and System Sciences, vol. 3, no. 2, 2010.

[10] X. Chen, J. Liang, S. Member, P. Li, and C. Choo, "UWB Electric and Magnetic Monopole Antennas,", African Journal Of Information And Communication Technology, vol. 2, no. 1, pp. 21-27, 2006.

[11] Noor Mohammed and Mohamed K. Abdelazeez, "Circular Patch UWB Antenna with Ground-Slot", IEEE Antennas and Propagation Society International Symposium (APSURSI), 2013.

[12] M. Ojaroudi and A. Faramarzi "Multiresonance small square slot antenna for ultra-wideband applications,", Microwave and Optical Technology Letters, Vol. 53, No. 9, September 2011.

[13] Sameer Alani, Zahriladha Zakaria and A. Ahmad "Miniaturized UWB elliptical patch antenna for skin cancer diagnosis imaging", International Journal of Electrical and Computer Engineering (IJECE), vol. 10, no. 2, pp.1422-1429, 2020.

[14] M. R. Ghaderi, and F. Mohajeri, "A Compact Hexagonal Wide-Slot Antenna With Microstrip-Fed Monopole for UWB. Application,", IEEE Antennas and Wireless Propogation Letters, vol. 10, pp. 682-685, 2011.

[15] M. E. Sundaravel, V. Al, and H. Sheker, "Compact Printed Slot UWB Monopole Antenna with Ground Plane Slit,", IOSR Journal of Electronics and Communication Engineering (IOSR-JECE), vol. 8, no. 3, pp. 25-30, 2013.

[16] M. A. A. Syeed, M. Samsuzzaman, M. Tarikul Islamc, R. Azimd and M. T. Islame "Polygonal Shaped Patch with Circular Slotted Ground Antenna for Ultra-Wideband Applications," 2018 Int. Conf. Comput. Commun. Chem. Mater. Electron. Eng., pp. 1-4.

[17] B. Azarm, J. Nourinia, C. Ghobadi, and M. Karamirad, "Ultra-Wideband Small Slot Antenna with WLAN BandNotched Function," no. February, 2018.

[18] A.S. Abdullah and M. J. Farhan, "Ultra Wideband Novel Printed Heptagonal Patch Antenna for Wireless Communication Applications", Journal of Al-Turath University Collage, pp. 1-24.

[19] Raad H. Thaher and Noor Baqqir Hassan "Proposed P-shaped Microstrip Antenna Array for Wireless Communcation Applications", TELKOMNIKA Indonesian Journal of Electrical Engineering, vol. 16, no. 6, pp.2597-2607, 2018.

[20] M T I. Huque, M K. Hosain, M S Islam, M A Chowdhury. "Design and performance analysis of microstrip array antennas with optimum Parameters for X-band aplications". International Journal of Advanced Computer Science and Applications (IJACSA), vol. 2, no.4, 2011.

[21] F. A. Shaikh, S. Khan, A. H. M. Zahirul Alam, D. Baillargeat, M. H. Habaebi, M. B. Yaacob, J. Shah, and Z. Shahid "Design and parametric evaluation of UWB antenna for array arrangement", Bulletin Of Electrical Engineering and Informatics (BEEI), vol. 8, no. 2, pp. 644-652, 2019.

[22] Ma T G, Jeng S K. "A Printed Dipole Antenna with Tapered Slot Feed for Ultra wide-Band Applications", IEEE Transactions on Antennas and Propegations, vol. 53, no. 11, 2005.

[23] S.De and P.P.Sarkar "A high gain ultra-wideband monopole antenna", International Journal of Electronics and Communications (AË̈), vol. 69, no. 8, pp.1113-1117, 2015.

[24] M. J. Farhan, "Gain Improvement of Ultra Wideband Patch Antenna for Transition Steps Hexagonal Patch as Array Antenna,", The International Arab Conference On Information Technology, pp. 145-150, 2014.

[25] M. J. Farhan and A. S. Abdullah "Design and Analysis of an Ultra Wideband Antenna with Printed Heptagonal Patch for Wireless Communication Applications", Computer Science and Applications, vol. 2, no. 2, pp.71-81,2015. 